\title{
MODEL PENGATURAN KEBIJAKAN PELAYANAN TERPADU PERPAJAKAN GUNA EFEKTIFITAS PELAYANAN PUBLIK (Studi Kasus Di Pemerintahan Kota Surakarta)
}

\author{
Guruh Raditya Warman \\ E-mail : guruh.raditya81@ gmail.com \\ Dinas PP, PA, dan PM Kota Surakarta \\ Fakultas Hukum Universitas Sebelas Maret Surakarta
}

Agus Riewanto . E-mail : agusriewanto@yahoo.com

I Gusti Ayu Ketut Rachmi Handayani. E-mail : ayu.igk@staff.uns.ac.id Fakultas Hukum Universitas Sebelas Maret Surakarta

\begin{abstract}
As stated in Local Regulation no. 4 Year 2011 on Surakarta Regional Tax on the enactment of Law of the Republic of Indonesia Number 28 Year 2009 on Regional Tax and Retribution, as an effort to maximize the PAD from the taxation sector in the region, it is necessary to facilitate the payment process because in the end one of the supporting factors for taxpayers will be orderly taxes if the local government provides convenience and facilities in the payment process or more popularly referred to the term excellent service. This article is about to find the model of policy regulation of integrated taxation services for the effectiveness of public services in Surakarta City Government, this research using the method of doctrinal approach (legal research) and method of nondoctrinal approach (socio legal research), which is qualitative. Keywords: Policy Settings; Integrated Services; Taxation; Public service
\end{abstract}

\begin{abstract}
Abstrak
Sebagaimana dinyatakan dalam Perda No. 4 Tahun 2011 tentang Pajak Daerah Kota Surakarta atas berlakunya Undang-Undang Republik Indonesia Nomor 28 Tahun 2009 tentang Pajak Daerah dan Retribusi Daerah, sebagai upaya memaksimalkan PAD dari sektor perpajakan di daerah, maka diperlukan adanya kemudahan dalam proses pembayaran karena pada akhirnya salah satu faktor pendukung bagi wajib pajak akan tertib pajak apabila pemerintah daerah memberikan kemudahan dan fasilitas dalam proses pembayaran atau yang lebih populer disebut dengan istilah pelayanan prima. Artikel ini hendak menemukan model pengaturan kebijakan pelayanan terpadu perpajakan guna efektifitas pelayanan publik di Pemerintah Kota Surakarta.,Penelitian ini dengan menggunakan metode pendekatan doktrinal (legal research) dan metode pendekatan non doktrinal (socio legal research), yang bersifat kualitatif.
\end{abstract}


Kata Kunci: Pengaturan Kebijakan; Pelayanan Terpadu; Perpajakan; Pelayanan Publik

\section{A. Pendahuluan}

Di Indonesia, dari masa ke masa, menjadi kewajiban negara untuk menyelenggarakan berbagai tugas yang berguna bagi masyarakat. Dengan tidak adanya organisasi yang luas beserta cabang-cabang dengan berbagai tugas-tugasnya, negara tidak mungkin dapat menunaikan tugasnya dengan baik. Untuk membiayainya, sudah barang tentu membutuhkan 'uang' dengan menjadikan pajak sebagai salah satu sumber pembiayaan dalam pelaksanaan dan peningkatan pembangunan nasional serta bertujuan untuk meningkatkan kemakmuran dan kesejahteraan masyarakat (R. Santoso, 2003:32). Penerimaan pajak merupakan sumber utama pembiayaan pemerintah dan pembangunan. Dasar hukum pemungutan pajak adalah Undang-Undang Dasar 1945 Pasal 23 ayat 2 yang menyebutkan "Segala pajak untuk kegunaan kas negara berdasarkan UndangUndang".

Pajak berfungsi untuk menutup biaya-biaya yang harus dikeluarkan oleh pemerintah dalam menjalankan pemerintahannya (fungsi budgetair). Fungsi ini merupakan fungsi yang utama dibandingkan dengan fungsi regulerend (fungsi mengatur), yaitu pajak dijadikan sebagai alat kebijakan pemerintah untuk mencapai tujuan-tujuan tertentu. Dalam APBN dan RAPBN, penerimaan pajak digolongan kepada penerimaan non-migas, yaitu terdiri atas: pajak penghasilan, pajak pertambahan nilai, bea masuk, cukai, pajak ekspor, pajak bumi dan bangunan, dan pajak lainnya (Markus Taufan, 2005:25).

Sistem perpajakan selalu mengalami perubahan dari masa ke masa sesuai perkembangan masyarakat dan Negara, baik dalam bidang kenegaraan maupun bidang dalam bidang sosial dan ekonomi. Pemungutan pajak merupakan suatu bentuk kewajiban warga Negara selaku Wajib Pajak serta peran aktif untuk membiayai berbagai keperluan Negara yaitu berupa pembangunan nasional yang pelaksanaannya diatur dalam undang-undang dan peraturan untuk tujuan kesejahteraan bangsa dan Negara. Penetapan pajak di Indonesia selalu didasarkan atas UU, sesuai amanat UUD 1945 dan 
amendemen, dalam ketentuan pasal 23 ayat (2) yang menyebutkan "Segala pajak untuk kegunaan kas negara berdasarkan Undang-Undang”.

Penetapan kebijakan desentralisasi fiskal dicanangkan oleh pemerintah pusat tanggal 1 januari 2001, sebagai tuntutan perubahan sentralisasi (UU No.5 tahun 1974) berubah menjadi desentralisasi (UU No.22 tahun 1999), kemudian dikuatkan dengan UU No. 23 tahun 2014 tentang Pemerintahan Daerah, bahwa pemerintah daerah diberikan wewenang untuk mengatur dan mengurus wilayahnya sendiri diharapkan dapat mengurangi ketimpangan wilayah. Desentralisasi tidak hanya dikaitkan dengan gagalnya perencanaan terpusat dan populernya strategi pertumbuhan dengan pemerataan, tetapi juga adanya kesadaran bahwa pembangunan adalah suatu proses yang kompleks dan penuh ketidakpastian yang tidak mudah dikendalikan dan direncanakan dari pusat.

Dalam rangka penyelenggaraan pembangunan dan menunjang pemerintahan daerahnya, pemerintah daerah berhak mengenakan pemungutan pajak daerah dan retribusi daerah kepada seluruh warga masyarakatnya (Ismail Tjip, 2011: 34-42). Menurut Marteen dan Robert (2002), Empat komponen sumber PAD tersebut khususnya pajak daerah dan retribusi daerah diharapkan dapat memberikan kontribusi yang positif untuk peningkatan PAD, yang menjelaskan bahwa peranan sektor pajak daerah dan retribusi yang paling besar kontribusinya terhadap PAD, yang dimana pengelolaannya diserahkan kepada pemerintah daerah itu sendiri (Marteen dan Robert, 2002: 351363).

Maka untuk menunjang hal diatas diharapkan pemerintah daerah mampu memberikan pelayanan publik yang baik, mendorong pertumbuhan ekonomi, menciptakan lapangan kerja baru, dan memperbaiki pendapatan masyarakat (Mahi Raksaka, 2002). Karena dengan hal tersebut akan menciptakan peningkatan penerimaan atau pendapatan daerah itu sendiri, serta salah satu faktor yang mempengaruhi peningkatan penerimaan pajak salah satunya adalah faktor ekonomi (Rizal Fariq Mustofa, 2011: 7).

Sebagaimana dinyatakan dalam Perda No. 4 Tahun 2011 tentang Pajak Daerah Kota Surakarta atas berlakunya Undang-Undang Republik Indonesia Nomor 28 Tahun 2009 tentang Pajak Daerah dan Retribusi Daerah, sebagai upaya memaksimalkan PAD dari sektor perpajakan di daerah, maka diperlukan adanya kemudahan dalam proses pembayaran karena pada akhirnya salah satu faktor pendukung bagi wajib pajak akan 
tertib pajak apabila pemerintah daerah memberikan kemudahan dan fasilitas dalam proses pembayaran atau yang lebih populer disebut dengan istilah pelayanan prima.

Pelayanan prima merupakan pelayanan yang diberikan oleh seluruh unit secara terintegrasi atau terpadu, baik di tingkat pimpinan sampai kepada bawahan, sehingga apa yang menjadi harapan pelanggan dapat dipuaskan. Definisi dari gambaran pelayanan prima tersebut mencakup: tingkat kecermatan (accurate), kecepatan pelayanan (fast), informative, kesederhanaan (simple), langsung (direct), harga yang pantas (reasonable), kenyamanan dan keramahan (courtesy) (Drajat Tri Kartono dkk. 2004:23).

Dalam melakukan pelayanan prima, Kota Surakarta menggunakan sistem self assessment dalam melakukan pemungutan pajak yang dilakukan oleh Dinas Pendapatan, Pengelolaan, Keuangan dan Aset (DPPKA) Kota Surakarta, berdasarkan Surat Keputusan Walikota Kepala Daerah KotamadyaSurakarta Tanggal 30 Juni 1972 No.162/Kep/Kdh.IV/Kp.72 tentang Penghapusan Bagian Pajak dari Dinas Pemerintahan Umum karena bertalian dengan pembentukan dinas baru. Dinas baru tersebut adalah Dinas Pendapatan Daerah yang kemudian sering disingkat DIPENDA.

Jiwa dari self assessment adalah pemerintah daerah dalam hal ini DPPKA yang memberi kepercayaan kepada Wajib Pajak untuk menghitung dan menetapkan sendiri besarnya kewajiban pajak yang harus dibayar Wajib Pajak. Perhitungan besarnya pajak ini harus diakui kebenarannya sebelum DPPKA dapat membuktikan yang sebaliknya, karena didalam asas self assessment ada unsur pendelegasian wewenang oleh DPPKA, maka sebagai konsekwensinya DIPENDA harus menciptakan sistem kontrol secara memadai, sebab pendelegasian wewenang tanpa kontrol akan mengakibatkan timbulnya penyalahgunaan wewenang.

Sebagai upaya memudahkan kontrol yang dilakukan DPPKA dan sekaligus memberi kemudahan bagi Wajib Pajak, maka Pelayanan perpajakan terpadu atau One Stop Service (OSS) perpajakan merupakan sebuah solusi yang dirasa tepat dan efisien (Moh. Ilham A. Hamudy, www.pikiranrakyat.com). OSS sendiri merupakan satuan kerja di tingkat pemerintahan kota/kabupaten yang secara khusus menyediakan pelayanan untuk memproses dokumen publik.

Berdasarkan apa yang telah diuraikan di atas, maka artikel ini hendak menemukan model model pengaturan kebijakan pelayanan terpadu perpajakan guna efektifitas pelayanan publik di Pemerintah Kota Surakarta. 


\section{B. Metode Penelitian}

Penelitian ini dilaksanakan di Dinas Pendapatan, Pengelolaan Keuangan dan Aset Kota Surakarta (DPPKA) Jl. Jend Sudirman No.2 Surakarta. Metode pendekatan yang digunakan dalam penelitian ini adalah metode doktrinal (legal research) dan metode non doktrinal (socio legal research), yang bersifat kualitatif. Kedua metode pendekatan ini diterapkan karena dalam penelitian ini disamping dipelajari peraturanperaturan perundangan, juga diteliti mengenai bagaimana fakta-fakta yang terjadi secara faktual dalam masyarakat, yang berkaitan dengan signifikansi sistem pelayana terpadu dalam Bidang Perpajakan Kota Surakarta.

Metode Penelitian kualitatif dikembangkan untuk mengkaji kehidupan manusia dalam kasus-kasus terbatas, kasuistis sifatnya, namun mendalam, total menyeluruh, dalam arti tidak mengenai pemilihan-pemilihan gejala secara konseptual ke dalam aspek-aspeknya yang eksekutif (disebut variabel). Dalam hubungan ini, metode kualitatif juga dikembangkan untuk mengungkapkan gejala-gejala kehidupan masyarakat itu sendiri tanpa intervensi oleh peneliti (Burhan Ashshofa, 2001:54).

Data penelitian yang dikumpulkan adalah data berupa bahan hukum primer berupa dokumen peraturan pelaksanaan kebijakan berdasarkan: a) Surat Keputusan Walikota Kepala Daerah Kotamadya Surakarta Tanggal 30 Juni 1972 No.162/Kep/Kdh.IV/Kp.72 tentang Penghapusan Bagian Pajak dari Dinas Pemerintahan Umum karena bertalian dengan pembentukan dinas baru; b) Undang-undang No. 16 tahun 2000 KUP; c) Undang-undang No.28 Tahun 2007 tentang Ketentuan Umum dan Tata Cara Perpajakan; d) Undang-undang No.17 tahun 2000 tentang tentang Pajak Penghasilan; e) UU No. 23 Tahun 2014 tentang Pemerintahan Daerah; dan f) UU Nomor 25 Tahun 2009 tentang Pelayanan Publik.

Data primer dalam bentuk wawancara dan observasi yang diperoleh secara langsung dari subjek penelitian (instansi) mengenai strategi pembayaran pajak dan hasil pembayaran pajak dari tahun 2013-2015 yang dilakukan oleh Dinas Pendapatan, Pengelolaan Keuangan dan Aset Kota Surakarta (DPPKA) sebagai representatif dari

pemerintah Kota Surakarta sebagai instansi pelaksana Pendapatan Asli Daerah (PAD).

Analisis data yang digunakan melalui 3 (tiga komponen pokok, yaitu: a) Data Reduction merupakan proses seleksi, pemfokusan, penyederhanaan dan abstraksi data 
kasar yang ada dalam field note; b) Data Display adalah rakitan organisasi informasi yang memungkinkan kesimpulan riset dilakuakan, sehingga peneliti akan dengan mudah memahami apa yang terjadi dan apa yang harus dilakukan; dan c) Canclution drawing dari awal pengumpulan data peneliti harus mengerti apa arti dari hal-hal yang ditelitinya, dengan cara pencatatan peraturan, pola-pola, pernyataan konfigurasi yang mapan dan arahan sebab akibat sehingga memudahkan dalam pengambilan kesimpulan.

Tiga komponen analisis data diatas membentuk interaksi dengan proses pengumpulan yang berbentuk siklus.

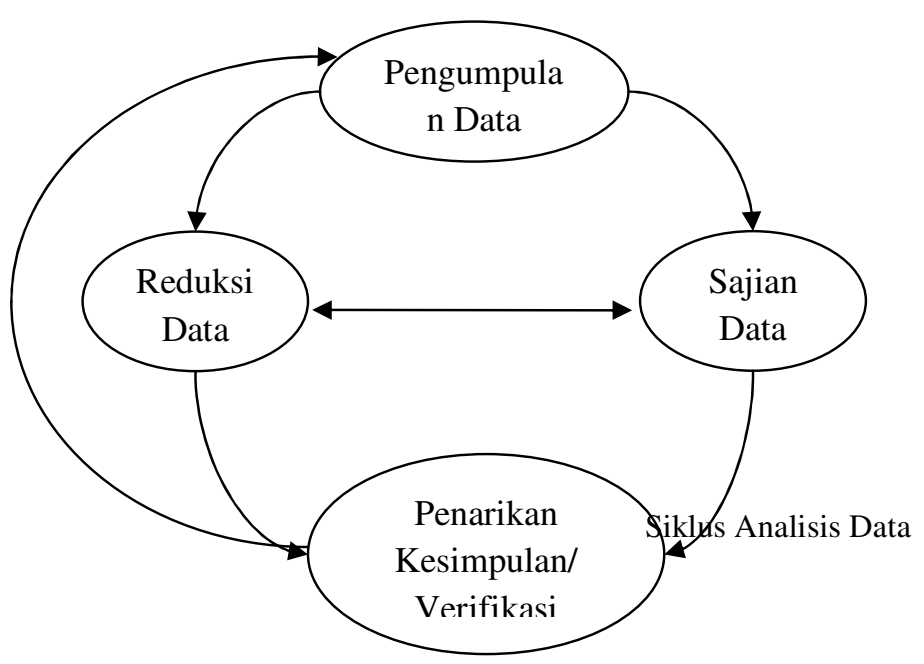

\section{Hasil Penelitian dan Pembahasan}

Kantor DPPKA Kota Surakarta selayaknya melakukan sebuah langkah inovasi yang progresif tersebut dalam rangka mendukung serta mengakomodir pelaksanaan tugas dan fungsi yang melekat pada Dinas Pendapatan Kota Surakarta dengan membuat sistem e-system ( penggunaan aplikasi basis data yang dikembangkan dalam jaringan online memungkinkan kecepatan akses informasi dan juga pelayanan pelaporan Surat Pemberitahuan/SPT dan pembayaran pajak secara 
online mengurangi administrative cost dan compliance costyang dikoneksikan melalui jaringan internet) terutama e-Payment, e-SPT, dan e-filing yang membantu kecepatan, ketepatan dan keamanan proses perekaman data administrasi pemenuhan kewajiban perpajakan wajib sebagai bentuk penigkatan mekanisme kontrol yang lebih efektif ditunjang dengan penerapan kode etik pegawai DPPKAD yang mengatur perilaku pegawai dalam melaksanakan tugas pada pengelolaan pajak. Hal ini tentunya sekaligus mendukung kebijakan Pemerintah Pusat dalam implementasi pelimpahan kewenangan pengelolaan pajak pada pemerintah daerah.

Adapun langkah-langka yang dapat dilakukan oleh Kantor DPPKAD Kota Surakarta dalam meningkatkan pelayanan hingga dapat terciptanya kepatuhan wajib pajak untuk mendapatkan penerimaan maksimal bagi daerah adalah:

\section{Reformasi Administrasi Perpajakan di Kantor DPPKAD Kota Surakarta}

Administrasi perpajakan merupakan cara-cara atau prosedur pengenaan dan pemungutan pajak. Dalam arti sempit, administrasi perpajakan merupakan penatausahaan dan pelayanan atas hak-hak dan kewajibankewajiban pembayar pajak yang dilakukan di kantor pajak maupun di tempat wajib pajak.

Mengenai peran administrasi perpajakan dikatakan efektif apabila Kantor DPPKAD Kota Surakarta mampu mengatasi masalah-masalah berikut ini (Pandiangan, Liberti dan Rayendra L. Toruan, 2008: 6-8): 1). wajib pajak tidak terdaftar (unregistered taxpayers); 2) wajib pajak yang tidak menyampaikan SPT (stop filling taxpayers); 3) penyelundup pajak (tax evaders). 4) penunggak pajak (delinquent tax payers).

Untuk menilai seberapa baik kemampuan administrasi perpajakan dalam mengumpulkan penerimaan, perlu diingat sasaran administrasi pajak yang harus diperhatikan oleh DPPKAD Kota Surakarta yakni peningkatkan kepatuhan pembayar pajak dan melaksanakan ketentuan perpajakan secara seragam untuk mendapatkan penerimaan maksimal dengan biaya yang optimal. Administrasi perpajakan dituntut bersifat dinamik sebagai upaya peningkatan penerapan kebijakan perpajakan yang efektif. Kriteria fisibilitas administrasi menuntut agar sistem pajak baru 
meminimalisir biaya administrasi (administrative cost) dan biaya kepatuhan (compliance cost) serta menjadikan administrasi pajak sebagai bagian kebijakan pajak.

Reformasi perpajakan meliputi dua area, yaitu reformasi kebijakan pajak (tax policy) yaitu regulasi atau peraturan perpajakan yang berupa undang-undang perpajakan dan reformasi administrasi perpajakan. Tujuan utama dari reformasi administrasi adalah (Gunadi, http://www.perspektif.net/articles/ view.asp?id=43): Pertama, untuk memberikan pelayanan kepada masyarakat dalam memenuhi kewajiban perpajakannya. Kedua, untuk mengadministrasikan penerimaan pajak sehingga transparansi dan akuntabilitas penerimaan sekaligus pengeluaran pembayaran dana dari pajak setiap saat bisa diketahui. Ketiga, untuk memberikan suatu pengawasan terhadap pelaksanan pemungutan pajak, terutama adalah kepada aparat pengumpul pajak, kepada Wajib Pajak, ataupun kepada masyarakat pembayar pajak.

\section{Modernisasi Struktur Organisasi}

Pembentukan organisasi berdasarkan fungsi Sebagai wujud pembenahan fungsi pelayanan, pengawasan dan pemeriksaan, struktur organisasi yang berdasarkan Keputusan Menteri Keuangan Nomor 443/KMK.01/2001 disusun menurut jenis pajak. Dengan diterapkannya sistem administrasi perpajakan modern struktur organisasi dirancang dengan paradigma berdasarkan fungsi dengan pemisahan fungsi yang jelas antara Kanwil dan KPP, dimana KPP bertanggung jawab melaksanakan fungsi pelayanan, pengawasan, penagihan dan pemeriksaan, sedangkan Kanwil bertanggungjawab melaksanakan fungsi pengawasan pelaksanaan operasional KPP, keberatan dan banding, serta penyidikan.

KPP Wajib Pajak Besar (Large Tax Office, LTO) dibentuk berdasarkan Keputusan Menteri Keungan Nomor 65/KMK.01/2002 yang terakhir diubah dengan Keputusan Menteri Keungan Nomor 587/KMK.01/2003, menangani Wajib Pajak besar nasional dengan kriteria jumlah peredaran usaha, jumlah pembayaran ataupun jumlah tunggakan pajaknya. Penerapan sistem administrasi perpajakan modern pada KPP Khusus yaitu KPP Badan Usaha Milik Negara (BUMN), KPP Penanaman Modal Asing (PMA), KPP Perusahaan Masuk Bursa (PMB), dan KPP Badan dan Orang Asing (Badora) berdasarkan Keputusan Menteri Keungan Nomor 
519/KMK.01/2003 jo. 587/KMK.01/2003. Selanjutnya dengan Keputusan Menteri Keungan Nomor 254/KMK.01/2004, dibentuk/ditetapkan KPP Madya (Middle Tax Office, MTO) yang menangani Wajib Pajak Badan Besar dalam lingkup kerja Kanwil, dan KPP Pratama (Small Tax Office, STO), yang menangani Wajib Pajak Badan kecil dan Wajib Pajak Orang Pribadi, dan Wajib Pajak Pajak Bumi dan Bangunan (PBB) dan Bea Perolehan Hak atas Tanah dan Bangunan (BPHTB).

\section{Modernisasi Prosedur Organisasi}

a. Pelayanan satu pintu melalui Account Representative/AR

Penunjukkan AR yang bertanggungjawab secara khusus melayani dan mengawasi administrasi perpajakan beberapa Wajib Pajak dengan mengembangkan konsep pelayanan satu pintu sehingga mengurangi persinggungan antara Wajib Pajak dengan petugas pajak yang kemungkinan dapat menimbulkan ekses negatif. AR juga menangani pemohonan Surat Keterangan Bebas (SKB) pajak, Pemindahbukuan Setoran Pajak (Pbk), ruling dan penerbitan produk hukum.

b. Penyederhanaan prosedur administrasi dan meningkatkan standar waktu dan kualitas pelayanan dan pemeriksaan pajak

Kegiatan yang dilakukan antara lain (i) menyederhanakan formulir Surat Pemberitahuan (SPT), (ii) mempercepat proses penyelesaian keberatan dan banding atas produk pajak, (iii) pengukuhan Wajib Pajak Patuh untuk mempercepat permohonan restitusi, (iv) meninjau kriteria Wajib Pajak Pungut untuk mengurangi permohonan restitusi, (v) meninjau kembali kewajiban pemeriksaan atas setiap Surat Pemberitahuan Lebih Bayar (SPT LB) dan mempercepat restitusi Surat Pemberitahuan Lebih Bayar (SPT LB) yang beresiko rendah, (vi) pemusatan Pajak Pertambahan Nilai (PPN).

c. Dukungan teknologi informasi modern dalam memberikan pelayanan, pengawasan, pemeriksaan dan penagihan pajak, antara lain:

1. SAPT terintegrasi dengan pendekatan fungsi dan prosedur administrasi yang telah diatur dalam case management dan workflow system didukung e-system, terutama $e$ Payment, e-SPT, dan e-filing yang membantu kecepatan, ketepatan dan keamanan proses perekaman data administrasi pemenuhan kewajiban perpajakan wajib pajak; 
2. Otomasi proses pemeriksaan dengan bantuan workflow management dalam SAPT membantu menghindari duplikasi data, kesalahan pencatatan dan pengawasan prosedural pemeriksaan sesuai dengan ketentuan peraturan perundang-undangan didukung juga dengan aplikasi Audit Command Language (ACL);

3. Pembangunan bank data dalam konsep masterplan secara nasional dan kerjasama pertukaran data dengan instansi lain mewujudkan transparansi data;

4. Otomasi penagihan pajak melalui SAPT sehingga prosedur pengawasan dan administrasi tunggakan pajak dapat selalu dilakukan. Pelaksanaan penagihan dilakukan jurusita pajak dengan metode hard dan soft collection, dimana soft collection dapat dilakukan dengan bantuan AR;

5. Melaksanakan pelatihan teknologi informasi;

6. Penggunaan teknologi informasi dan e-system lainnya Dalam menjalankan administrasi perpajakan dan meningkatkan pelayanan dikembangkan aplikasi seperti e-Regristation, e-Counseling, Complaint Center, Help Desk, Call Center, Touch Screen yang didukung Knowledge Base yang berisi Frequently Asked Question (FAQ), SMS tax, dan saluran komunikasi dan penyuluhan yang lebih intensif melalui berbagai sarana seperti telepon, e-mail, portal website, pencatatan dan penyimpanan dokumen yang lebih dapat diandalkan menggunakan Sistem Manajemen Arsip Terpadu (SMArT), dukungan peralatan perkantoran yang modern, lengkap, dimana tiap pegawai dilengkapi personal computer dan akses informasi yang lebih cepat baik dalam lingkungan interen maupun kepada wajib pajak dimana tiap terdapat perubahan ketentuan menyangkut wajib pajak akan segera dikonsolidasikan secara internal, diinterpretasikan dan selanjutnya segera diinformasikan kepada wajib pajak.

d. Fasilitas perkantoran modern

Perkantoran modern dengan keseluruhan operasi berbasis teknologi dengan pengadaan sarana dan prasarana yang memenuhi persyaratan mutu dan menunjang upaya modernisasi administrasi perpajakan di seluruh Indonesia.

\section{e. Modernisasi Strategi Organisasi}

1) Kampanye sadar dan peduli pajak;

2) Simplifikasi administrasi perpajakan; dan

3) Intensifikasi penerimaan pajak.

f. Modernisasi Budaya Organisasi 
Program penerapan pemerintahan yang bersih dan berwibawa (good governace) (Chaizi Nasucha, 200443-45): 1) Menerapkan kode etik terhadap seluruh pegawai Direktorat Jenderal Pajak. Good governance dicirikan oleh adanya kode etik Pegawai Direktorat Jenderal Pajak berdasarkan Keputusan Menteri Keuangan Nomor 222/KMK.03/2002 tanggal 14 Mei 2002 sebagaimana telah diubah terakhir dengan Peraturan Menteri Keuangan Nomor 1/PM.3/2007 tanggal 23 Juli 2007; dan 2) penyiapan sumber daya manusia (SDM) yang berkualitas dan profesional, antara lain melalui pelaksanaan fit and proper test secara ketat, penempatan pegawai yang disesuaikan dengan kapasitas dan kapabilitasnya, reorganisasi, kaderisasi, pelatihan dan pogram pengembangan self capacity, reward and punishmen, reformasi moral dan etika.

\section{g. Peningkatan Kualitas Sumber Daya Manusia (SDM)}

Salah satu poin penting dalam penerapan Sistem Administrasi Modern Reformasi di Kantor DPPKA Kota Surakarta difokuskan kepada pengembangan sumber daya manusia dan penggunaan teknologi informasi dalam administrasi perpajakan. Pengelolaan terhadap sumber daya manusia merupakan sebuah perubahan subtansial dan belum pernah dijalankan pada perubahan sebelumnya. Besarnya perubahan yang dilakukan dalam Reformasi Perpajakan tampak sebagai upaya mewujudkan aparatur yang berkualitas secara intelektual dan moral.

\section{Simpulan}

Model Kebijakan Pelayanan Terpadu Perpajakan Yang Ideal di Pemerintahan Kota Surakarta Guna Mewujudkan Efektifitas Pelayanan Publik adalah dengan pentingnya melakukan 6 (enam) tindakan, diantaranya: a) Mereformasi administrasi perpajakan; b) Melakukan modernisasi struktur organisasi; c) Melakukan modernisasi prosedur organisasi; d) Melakukan modernisasi strategi organisasi; e) Melakukan modernisasi budaya organisasi; dan f) Meningkatkan Kualitas Sumber Daya Manusia (SDM).

\section{E. Saran}

1. Agar lebih meningkatkan upaya dalam mengintensifikasi dengan peningkatkan kualitas pelayanan terhadap wajib pajak, menyusun system informasi dan prosedur pengelolaan pajak daerah, agar masyarakat luas dapat mengetahui dan mengakses system tersebut. 
2. Dalam mengoptimalkan PAD melalui pajak daerah tentunya memiliki banyak faktor yang mempengaruhinya. Faktor-faktor berpengaruh paling mendasar yang harus segera ditingkatkan oleh pemerintah daerah Kota Surakarta adalah: a) Sumber daya manusia di masing- masing dinas penghasil pajak daerah b) Kerjasama antar bidang / instansi yang harmonis dan tidak mementingkan ego sektoral dalam dinas di Pemerintah Kota Surakarta; dan c) Hubungan kemitraan dengan masyarakat.

3. Penyiapan perangkat hukum yang bertanggungjawab untuk menghilangkan kemungkinan pelanggaran yang dilakukan aparatur/petugas pajak terjadi, misalnya tindakan seperti pungutan liar. Karena bagaimanapun keberadaan

4. pungutan liar menjadi masalah yang aparat yang berwenang ikut minta mempengaruhi pajak daerah jika bagian dalam pungutan liar. 


\section{F. Daftar Pustaka}

Burhan Ashshofa. 2001. Metode Penelitian Hukum, Jakarta, PT. Rineke Cipta.

Chaizi Nasucha. 2004. Reformasi Administrasi Publik: Teori dan Praktik, Jakarta; PT Gramedia Widiasarana Indonesia.

Devas (1997) dalam Mujiyati dan Abdul Aris. 2011. Perpajakan Kontempoter. Surakarta, Universitas Muhamadiyah Surakarta.

Dimas Ramadiansyah, Nengah sudjana dan dwiatmanto. 2014. "Analisi Faktor-Faktor yang Mempengaruhi Wajib Pajak dalam Memenuhi KewajibanMembanyar Pajak." Jurnal Akuntansi Perpajakan Nomor 1 Volume 1. Malang, Universitas Brawijaya.

Drajat Tri Kartono dkk. 2004. Administrasi Pelayanan Publik (Antara paradoks dan Harapan Masa Depan). Surakarta; Pustaka Cakra.

Gunadi. "Keberhasilan Pajak Tergantung Partisipasi Masyarakat," Dalam Perspektif Baru, URL: http://www.perspektif.net/articles/ view.asp?id=43 1, 27 September 2003, diakses tgl 26 Desember 2016, Jam 22.10

Ismail Tjip, 2011. "Paradigm Change of Local Tax." Journal of administrative Science and Organization. Vol 18 No 1.

Mahi Raksaka, 2002. "Managing Local Revenue in Indonesia." Journal of Georgia University, Atlanta.

Mardiasmo. 20111. Perpajakan, Jakarta, Salemba Empat.

Markus Taufan, 2005. "Pengaruh Penerapan Sistem Administrasi Perpajakan Modern Terhadap Kepatuhan Wajib Pajak Pada Kantor Pelayanan Pajak Di Lingkungan Kantor Wilayah Direktorat Jenderal Pajak Wajib Pajak Besar" Penelitian. Jakarta; Sekolah Tinggi Akuntansi Negara.

Marteen, et all. 2001. Partisan Influence on the Local Tax Burden in the Netherland. Public Choise. 
Moh. Ilham A. Hamudy. 2010. Makalah; Serap Investasi dengan Pelayanan Terpadu. www.pikiranrakyat.com. Diakses 23 Maret 2016.

Pandiangan, Liberti dan Rayendra L. Toruan. 2008, Modernisasi dan Reformasi Pelayanan Perpajakan: Berdasarkan UU Terbaru 2008. Jakarta, Elex Media Komputindo.

Rizal Fariq Mustofa. 2011. "Determinant of Tax Complience in Asia: A Case Of Malasya.” European Journal of Social Science. Vol 24 No 1.

Robert A. Simanjuntak, 2002. "Evaluation Criteria an the Efforts to Increase Local Tax Base A Case Study of Indonesia Decentralizing Era." Journal of Georgia State University. Atalanta.

R. Santoso Brotodihardjo S.H,. 2003. Ketentuan Umum dan Tata Cara Perpajakan (KUP), Cet. Ke-2. Jakarta; Refika Aditama.

Siti Kurnia Rahayu, 2010. Perpajakan Indonesia : Konsep dan Aspek Formal, Yogyakarta, Graha Ilmu. 